\title{
Organização dos serviços na atenção à saúde da idosa:
}

\section{percepção de usuárias}

Suzane Gomes de Medeiros ${ }^{(a)}$

Fátima Raquel Rosado Morais(b)

Medeiros SG, Morais FRR. Organization of healthcare services for elderly women: users' perceptions. Interface (Botucatu). 2015; 19(52):109-19.

The aim of this study was to ascertain the factors that interact in care for elderly women in the municipality of Mossoró, Rio Grande do Norte, Brazil, from the users' perspective. This study took a descriptive and qualitative approach and was carried out among women aged 60 years or over who used the primary care services selected for this study. From analysis on testimonies, three categories emerged: reasons for seeking the healthcare service; medical guidance received from the healthcare service and everyday problems faced on seeking services. Quality of care for elderly women requires trained workers, reduction of bureaucratic obstacles and continuous linked-up actions and practices that take into account elderly women's desires and expectations.

Keywords: Elderly woman. Primary care. Aging.
Objetiva-se apreender os aspectos que interatuam na assistência à mulher idosa no município de Mossoró-RN, Brasil, a partir da perspectiva das usuárias. Pesquisa de natureza descritiva e abordagem qualitativa, realizada com mulheres na faixa etária dos sessenta anos ou mais, que utilizam os serviços de atenção básica selecionados para o estudo. Após a análise dos depoimentos, emergiram três categorias: motivos que estimulam a procura do serviço; orientações recebidas nos serviços de saúde, e problemáticas cotidianamente vivenciadas na procura do serviço. A qualidade da atenção à mulher idosa requer trabalhadores capacitados; diminuição dos entraves burocráticos; ações e práticas articuladas e contínuas, contemplando anseios e expectativas da idosa.

Palavras-chave: Mulher idosa. Atenção Básica. Envelhecimento.

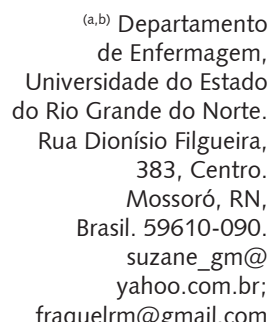

(a,b) Departamento de Enfermagem, Universidade do Estado do Rio Grande do Norte. Rua Dionísio Filgueira, 383, Centro. Mossoró, RN, Brasil. 59610-090 suzane_gm@ yahoo.com.br; 


\section{Introdução}

No Brasil, a pessoa que tem sessenta anos ou mais é considerada idosa - processo natural, irreversível e mundial. O país aponta para uma estrutura etária cada vez mais envelhecida, o que implica adequações das políticas, especialmente as de saúde, para atender esta parcela da população ${ }^{1}$.

No país, a expectativa de vida na década de 1970 era de 57,1 anos². No período entre 1960 a 2006, evidencia-se um avanço na faixa etária, com diferença entre homens e mulheres. Em 2006, a disparidade na idade entre os sexos era de 7,6 anos. Os homens atingiam 68,5 anos e as mulheres $76,1^{3}$.

Assim, no contexto brasileiro, há uma tendência para que as mulheres alcancem idades maiores do que homens, com predominância de idosas, pois a mortalidade atinge os homens em proporção mais elevada, caracterizando o fenômeno da feminização da velhice ${ }^{4}$.

O envelhecimento populacional em nível mundial, também acompanhado pelo Brasil, é associado, ainda, a uma modificação epidemiológica permeada por doenças. Isso incrementa as responsabilidades na área da saúde no enfrentamento das necessidades da população idosa, no intuito de garantir os direitos destes cidadãos ${ }^{5}$. Considerando que a população feminina em processo de envelhecimento aumenta vertiginosamente, faz-se pertinente que as políticas sejam elaboradas para atender às especificidades deste público.

A disposição contemporânea na pirâmide demográfica nos dias atuais mostra que a base estreitada e o ápice mais alargado para o sexo feminino representam um fenômeno acelerado e real ${ }^{1}$. Sendo assim, respeitar e proporcionar à idosa uma assistência integral, que contemple suas necessidades e singularidades, deve ser uma preocupação de todos, na perspectiva de viabilizar qualidade de vida a sua existência.

O envelhecimento no Brasil tem acarretado, para o governo, a produção de novas políticas públicas, pois, em geral, essa fase da vida encontra-se associada ao aparecimento de diversas problemáticas, desvelando a importância de práticas inovadoras de planejamento, acesso e manutenção do atendimento ao idoso ${ }^{6}$. Pensar ações nessa dimensão tende a gerar avanços na vida da idosa em termos de funcionalidade, proteção, integração social e de saúde.

Todavia, os serviços parecem, ainda, não estar adequadamente preparados para atuar mediante as particularidades da pessoa idosa. É comum a existência de dificuldades na gestão e operacionalização de estratégias inovadoras e efetivas que contemplem prioridades de saúde da população. A rotina de se adotarem programas previamente formatados, independente dos contextos e particularidades que os caracterizam, torna mais difícil, e até mesmo inviabiliza, a apreensão da qualidade na assistência ${ }^{8}$. Nisso, as propostas implementadas não conseguem dar conta das necessidades sociais, biológicas, físicas e culturais das usuárias que buscam as instituições de saúde ${ }^{7}$, o que acaba gerando insatisfação da população. No geral, esses programas se constituem como instrumentos "engessados", que não suprem as expectativas dos profissionais e da clientela coexistentes nesta dinâmica.

Assim, torna-se preciso refletir acerca da organização da atenção à saúde da população idosa, em particular das mulheres ${ }^{7}$, grupo predominante na busca pelos serviços de saúde, o que demonstra a relevância de se conhecer o perfil e as necessidades dessas usuárias.

Nessa dimensão, esse estudo objetiva apreender os aspectos que interatuam na assistência à mulher idosa no município de Mossoró-RN, a partir da perspectiva das usuárias. Os resultados dessa investigação podem contribuir para refletir sobre os espaços e o saber/fazer na atenção ao envelhecimento, apontando para a reorientação da dinâmica cotidiana no processo assistencial.

\section{Metodologia}

A presente pesquisa representa o recorte de um estudo maior que culminou com uma dissertação apresentada ao Mestrado acadêmico em Saúde e Sociedade, da Universidade do Estado do Rio Grande do Norte. Esse recorte é a etapa de natureza descritiva e abordagem qualitativa, realizada com mulheres idosas, no município de Mossoró, Rio Grande do Norte, Brasil. 
O estudo foi desenvolvido em oito Unidades Básicas de Saúde (UBS), localizadas nas zonas norte, sul, leste e oeste da cidade. Esta divisão foi estabelecida como forma de melhor investigar, nas diferentes áreas geográficas, os aspectos que envolvem o cuidado prestado à população feminina que envelhece. Para cada zona, foram selecionadas, por meio de sorteio, duas unidades de saúde compostas por equipes da Estratégia Saúde da Família (ESF).

As UBS selecionadas e suas respectivas zonas foram: UBS Cid Salém Duarte e UBS Luiz Escolástico Bezerra, zona norte; UBS Dr. Chico Costa e UBS Dr. Ildone Cavalcante de Freitas, zona leste; UBS Vereador Durval Costa e UBS Dr. Agnaldo Pereira, zona sul; e, por fim, UBS Marcos Raimundo da Costa e UBS Dr. José Fernandes de Melo, zona oeste.

A população da investigação foram mulheres na faixa etária a partir dos sessenta anos, que utilizavam os serviços de saúde selecionados para a pesquisa. Para a escolha das respondentes, utilizou-se o critério de amostragem não probabilística do tipo intencional, sendo entrevistadas idosas que estavam utilizando os serviços das unidades no momento da coleta dos dados.

Para a idosa participar da pesquisa, foram critérios de inclusão: ser assistida na unidade, ter idade igual ou superior a sessenta anos e ser do sexo feminino; e de exclusão: não apresentar distúrbios mentais e não utilizar os serviços da unidade básica rotineiramente.

O instrumento para a coleta dos dados foi um roteiro de entrevista semiestruturado, estratégia muito utilizada em trabalho de campo por proporcionar flexibilidade na conversa ${ }^{9}$. O roteiro continha 14 questões abertas que versavam acerca da concepção das idosas sobre o seu estado de saúde e a qualidade do atendimento na UBS.

Para a definição da amostra, foi adotado o critério de significância, pois, na pesquisa principal, foi aplicado um questionário com 361 idosas. Nessa etapa qualitativa, optou-se por realizar as entrevistas com $10 \%$ dessa amostra, perfazendo um total de 36 mulheres, por se entender que os discursos obtidos representariam o grupo ora em destaque.

Assim, a proporção de idosas selecionadas para responder ao roteiro de entrevista qualitativo nas oito UBS corresponde a uma média de quatro idosas por unidade de saúde, ou seja, 32 mulheres. Para completar a amostra definida, nas quatro unidades com o maior número de idosas cadastradas, foram realizadas cinco entrevistas, ao invés de quatro. A coleta dos dados aconteceu entre os meses de novembro de 2012 e março de 2013.

Para a análise dos dados, o material foi transcrito, sofreu sucessivas leituras e foram retiradas categorias de sentido a partir do objetivo da investigação. O referencial que norteou essa investigação teve seu fundamento embasado na avaliação da atenção à saúde para a população idosa. Para tal, foram utilizadas referências que discutem: avaliação da assistência ${ }^{10-12}$, produção dos serviços de saúde ${ }^{11}$, práticas para as idosas nos serviços de saúde ${ }^{13-15}$, direitos legais para idosos ${ }^{16}$, dentre outros aspectos.

A pesquisa foi aprovada pelo Comitê de Ética em Pesquisa da Universidade do Estado do Rio Grande do Norte.

\section{Resultados e discussão}

As percepções das participantes do estudo acerca da organização dos serviços de atenção à saúde voltada para a mulher idosa no município de Mossoró apontaram para a construção das seguintes categorias: "motivos que estimulam a procura do serviço"; "orientações recebidas nos serviços de saúde" e "problemáticas cotidianamente vivenciadas na procura do serviço".

\section{Motivos que estimulam a procura do serviço}

Em razão do envelhecimento e das especificidades de atenção à população idosa, existe uma tendência crescente na procura por serviços de saúde. Relacionado às necessidades de saúde, as mulheres são as que mais frequentemente procuram agendar consultas para avaliação rotineira semestral ou anual. Os homens apresentam percentual inferior ${ }^{10}$. 
Uma provável explicação para essa assiduidade do público feminino a esses serviços está atrelada a maior atenção sobre questões de saúde. Ainda existe tendência cultural que vincula mais vulnerabilidade às mulheres quanto aos problemas de saúde ${ }^{11}$.

Essa perspectiva é confirmada nesse estudo quando se encontram idosas cônscias da importância do acompanhamento com profissionais de saúde, para adequado atendimento das suas necessidades.

“Eu comecei a me tratar faz muitos anos. [...] Eu acho ótimo o acompanhamento porque a gente tem que se cuidar não é? Fazer a prevenção, fazer mamografia. Eu sempre vou ao médico cardiologista, ao dermatologista, ao reumatologista". (I3)

"A gente vem para tentar se prevenir não é? Também assim, para fazer o exame de prevenção, e sempre que estiver precisando. Mas também venho pegar medicação". (I16)

“Eu venho para me prevenir, eu repito os meus exames todinhos, exames de sangue, de tudo! Para saber se estou com alguma coisa". (I17)

Em função da variedade de necessidades, essa busca periódica por atendimento na área da saúde exige uma boa qualificação dos profissionais para ofertar um apoio voltado para as reais especificidades desta população. Foi perceptível que algumas idosas vivenciam este processo de visitas ao posto de saúde como uma forma de prevenção de doenças. Para outras, a unidade representa um ambiente para receber medicações de uso contínuo e fazer procedimentos diversos que estejam disponíveis para estas mulheres.

Em função das mudanças no perfil populacional e no padrão de saúde dos brasileiros que atingem idade avançada, faz-se necessária a reorganização dos serviços de saúde com foco na dimensão preventiva de atuação. Desta forma, é preciso incentivar esta prática de promoção e prevenção, contribuindo para a melhoria da qualidade de vida destas usuárias.

Apesar de os discursos, em geral, apontarem a prevenção como dimensão que incentiva a busca pelas instituições de saúde, a procura ainda acontece apenas em face da enfermidade.

"Quando eu não estou me sentindo bem eu venho, mas eu não estando sentindo nada eu não venho. Quando eu sinto que estou precisando eu venho". (I19)

"Para que eu tenha uma saúde não perfeita, mas regular. Venho quando estou doente, mas também todo ano eu faço um check-up para ver como é que está não é? Para viver bem". (I29)

“[...] Todos os meses eu venho, é difícil ter um mês para eu não vir. [...] Eu vivo doente não é? Aí procuro o centro de saúde, os médicos". (I30)

Outro estudo ${ }^{10}$ evidenciou que a maioria da população idosa busca a consulta médica apenas quando está doente. Nessa investigação, apesar de parte das usuárias enfatizar a dimensão da prática preventiva, ainda foi evidenciado que muitas idosas só procuram os serviços mediante alguma afecção, sem um cuidado prévio para evitar que os distúrbios se agravem.

Assim, faz-se pertinente fornecer orientações para esta população na tentativa de prevenir determinadas doenças e beneficiar a saúde da mulher que envelhece. Esta demanda feminina em busca de cuidados com a saúde deve ser observada pelos profissionais que atendem este público, articulando ações que promovam um cuidado integral, respeitando as particularidades.

\section{Orientações recebidas nos serviços de saúde}

Na dimensão das ações educativas para adesão às práticas saudáveis, as participantes foram questionadas quanto às orientações acerca dos cuidados com a saúde da mulher idosa, durante o acompanhamento na unidade: 
"Recebo! Muita orientação. E eu também tenho as minhas orientações, sei que eu não posso comer aquela comida, então não vou tentar". (I3)

“Não. Essas coisas de queda, alimentação eu sei por que a gente sabe que é assim mesmo, mas que nunca chegou para dizer assim: é para fazer isso, para fazer aquilo, nunca chegou ninguém". (124)

“Elas falam para ter cuidado para não cair, evitar fraturas, também a pressão tem que verificar todos os dias, além de tomar o remédio tem que verificar a pressão, fazem recomendações nas reuniões, quando tem". (I31)

As orientações advindas dos profissionais de saúde são essenciais para que as idosas aprendam a lidar com as doenças e limitações que a velhice naturalmente impõe. No entanto, a partir dos discursos, evidenciou-se que essa conduta nem sempre é priorizada nas consultas. Em alguns casos, a ausência destas recomendações pode sugerir uma assistência fragilizada e falta de capacitação dos profissionais, o que, consequentemente, repercute na saúde dessa população.

De acordo com a Política Nacional de Saúde da Pessoa Idosa, atualmente, faltam profissionais em quantidade adequada para o atendimento apropriado dessa clientela. Logo, é um desafio a constituição de uma rede de cuidado e apoio qualificados, assim como a conformação de equipes interdisciplinares e multiprofissionais com saberes em saúde sobre envelhecimento para a pessoa idosa ${ }^{12}$.

Nos relatos, os profissionais que acompanham as idosas nem sempre ofertam uma consulta qualificada, sendo, por vezes, rápida, apressada. Nesse contexto, as mulheres em geral não ficam à vontade para perguntar e esclarecer suas queixas.

“Às vezes quem não dá atenção são os médicos. Tem deles que não dá tempo nem a gente sentar, já mandam a gente se levantar". (I12)

“[...] Às vezes a gente tem vontade de falar e perguntar alguma coisa, mas aquela consulta é tão rápida que eles ficam... A gente falando alguma coisa e eles lá escrevendo, e a gente fica até com vergonha de ficar falando e eles escrevendo e a gente atrapalhando". (I20)

Quando questionadas a respeito da consulta, a maioria das entrevistadas associa esta conduta ao médico, aspecto evidenciado nos discursos. No entanto, na atenção primária, os atendimentos são feitos por diversas categorias de trabalhadores, como os da enfermagem, da medicina, da odontologia, dentre outros.

Embora existam profissionais que não permitem abertura para que a idosa pergunte, uma vez que a consulta é feita em pouco tempo, faz-se necessário que condutas mais interacionais sejam estabelecidas, proporcionando que a idosa seja contemplada em suas prioridades.

Todavia, ainda são encontradas, nos serviços de saúde, pessoas capazes de fornecer uma atenção de qualidade para este público, escutando suas queixas e orientando as condutas a serem seguidas no acompanhamento que recebem no posto.

"Aqui todos me atendem direito, eu me sinto à vontade aqui na consulta". (I19)

"Quando eu venho para a consulta eu me sinto à vontade para perguntar, retirar minhas dúvidas, dizer o que estou sentindo. Eles me explicam as coisas, o ano passado eu fiz prevenção com uma enfermeira daqui e, gostei muito, ela é uma pessoa boa, faz bem". (I18)

Esta assistência voltada para a idosa e entendida como boa, deixando-a livre para fazer perguntas, pode ser refletida a partir da perspectiva de que alguns profissionais estão mais bem capacitados para desenvolver uma atenção com foco nas singularidades destas pessoas. Assim, esse tipo de atendimento deve ser prioridade nos cuidados envolvendo a paciente que envelhece. 
As necessidades específicas da mulher idosa não podem ser quantificadas. O aumento na expectativa de vida terá relação intrínseca com a produção do cuidado ofertado às mulheres que envelhecem. De fato, entender o fenômeno do envelhecimento e as demandas biopsicossociais vivenciadas pelas idosas facilitará a elaboração das práticas destinadas ao grupo ${ }^{13}$. É preciso compreender os aspectos subjetivos de modo a entender as experiências determinantes nessa etapa da vida e os cuidados necessários neste período.

Um ambiente favorável para que discussões sobre cuidados em saúde sejam disseminadas é por meio da formação de grupos de idosos, pois possibilita troca de conhecimentos diversos e, inclusive, relacionados à saúde. Favorece, ainda, o envolvimento das mulheres idosas da comunidade, contribuindo para que se tornem mais independentes nos cuidados com a saúde pessoal.

Em outro estudo ${ }^{14}$, o grupo é entendido não apenas como um espaço de lazer e passatempo diário, mas como uma alternativa de viver saudável e do aumento de redes sociais. São estabelecidos laços de afeto, se garante companhia, conhecimento e entretenimento, conforme observado nos relatos:

“[...] na penúltima quarta-feira do mês tem uma reunião dos hipertensos, aí nos reunimos e a enfermeira dá muitas explicações a gente, orientações. [...] aí eu participo do grupo de idosos aqui do posto". (I33)

"Aí sempre eu vou. Todas as quartas-feiras tem. É o grupo dos idosos que eu participo, tem palestra, tem passeio, tem dança para quem quiser dançar e quem não quer tem o baralho lá para jogar, quem não quer vai se divertir para conversar, e é assim. Eu acho bom demais [...]". (I25)

Na concepção das idosas que participam de atividades grupais, esta é uma maneira de melhor desfrutar desta etapa da vida em que se encontram. Nestes locais, são construídos vínculos com os outros participantes, o que é definido como uma busca pelo ideal de uma velhice mais saudável ${ }^{14}$.

Em razão dos discursos acima, percebe-se que a participação no grupo representa um espaço para as mulheres vivenciarem momentos de interação com outras pessoas. As reuniões facilitam a oportunidade de tirar dúvidas, receber orientações e discutir acerca de questões voltadas para o interesse das idosas.

Em nosso país, determinados grupos sociais, como o da mulher idosa, estão à margem, sofrem devido à exclusão social. Isto decorre de duplo preconceito: ser idosa e ser mulher, o que tende a desestimular o engajamento em ações que propiciariam prazer. Neste aspecto, os grupos de convivência são dispositivos importantes para atenuar as dificuldades decorrentes do processo de envelhecimento. Tais grupos são denominados, pelas pessoas que o compõem, como um espaço social capaz de resgatar a autoestima ou de reinserção, uma vez que muitas delas passam a sentir-se excluídas ${ }^{14}$.

A participação em grupos promove, aos integrantes, o aumento do saber de si e do outro, por meio de conversas e troca de informações nesse espaço. Caracteriza sua importância o fato de constituir espaço privilegiado como meio de ensino/aprendizagem e para o efetivo controle social ${ }^{15}$. Os grupos de idosos, como em geral são denominados, possuem, como principais participantes, as mulheres, sendo os homens minoria nestes encontros.

A importância do engajamento no grupo se deve em razão de que, nem sempre, as dúvidas sobre o estado de saúde são esclarecidas no atendimento de rotina na unidade básica ${ }^{15}$. Algumas idosas possuem incertezas acerca das doenças que as acometem, o que contribui para um cuidado ineficaz.

"Porque eu tenho muitas dúvidas de certos problemas de saúde, por exemplo, o ácido úrico que eu não entendo o que é. Sei que é uma coisa que me incomoda bastante, não posso comer isso, não posso comer aquilo, não consigo um nutricionista, aí como isso está na família, eu tenho uma irmã que tinha esse problema então eu estou fazendo do meu jeito não é? Mas eu queria muito saber o que é ácido úrico, que eu não entendo". (16) 
Evidencia-se, assim, que os serviços de saúde ainda apresentam carências em relação às orientações fornecidas à mulher idosa, o que demonstra uma organização dos serviços de saúde em função de demandas básicas. Quando a necessidade da idosa se especializa, há uma tendência ao não-atendimento das carências das usuárias.

\section{Problemáticas cotidianamente vivenciadas na procura do serviço}

Para o acompanhamento na unidade de saúde garantir os direitos assegurados em lei à população idosa feminina, algumas prioridades precisam ser gestadas para definição de estratégias que culminem com a qualidade no atendimento.

O Estatuto do Idoso, Lei no 10.741 , de $1^{\circ}$ de outubro de 2003, em seu artigo $3^{\circ}$, parágrafo único, inciso I, aborda o "atendimento preferencial imediato e individualizado junto aos órgãos públicos e privados prestadores de serviços à população"16 (p. 8). Conhecido pela grande maioria da população, inclusive das idosas, o atendimento com prioridade é algo que ainda precisa ser revisto nos serviços de saúde, uma vez que relatos dão conta do descumprimento desse direito:

“[...] a área da saúde hoje é muito difícil. E a procura das pessoas é muito grande. Aí tem que atender as pessoas em ordem". (I14)

"[...] Aqui a gente tem prioridade, sempre os idosos têm prioridade, agora é porque hoje em dia tem muita gente com prioridade também, aí a gente tem que esperar um pouco não é?". (115)

"Aqui a gente não tem preferência, nem pelo fato de eu ser idosa, tem que esperar. E eu espero, às vezes entra gente na frente, porque dizem que não pode entrar, mas eu também não ligo para isso não". (123)

A preferência no atendimento é um direito da pessoa com sessenta anos ou mais, e esta população reconhece os seus direitos nesse quesito. Todavia, o incremento da população idosa, além de questões relacionadas ao desrespeito a um direito garantido, tem gerado ausência de prioridade no atendimento nas unidades de saúde, ficando a consulta em espera, estabelecida pela ordem de chegada.

O serviço público é utilizado pela maioria dos idosos quando precisam de atendimento do profissional de saúde. Essa elevada demanda é reflexo do aumento da prevalência de doenças crônicas não transmissíveis, que precisam de tratamento por longo período de tempo e de forma contínua ${ }^{17}$.

Outra dificuldade caracteriza-se pelas questões clínicas inerentes à vida da idosa. Devido à presença de morbidades, existe a necessidade de utilização rotineira de medicamentos para tratar suas afecções, uma vez que as doenças crônicas podem refletir negativamente na qualidade de vida ${ }^{18}$.

Em razão do envelhecimento populacional em nosso país, cresce uma tendência ao consumo de medicamentos, em que as iatrogenias apresentam outras características, sendo preciso medicações cada vez mais eficientes e de baixo custo, associado à ampliação dos serviços de saúde, para que as reais especificidades destes sujeitos sejam contempladas ${ }^{10}$.

As medicações utilizadas pela população idosa para o controle de várias doenças são, em sua maioria, distribuídas nos postos de saúde, aspecto positivo para tratar patologias diversas. No entanto, há situações nas quais existe falta de determinados medicamentos, sendo necessário ou conseguir em outra unidade ou comprá-los, o que influencia, por vezes, na interrupção do tratamento. Nem todas as idosas possuem condições financeiras para comprar as medicações que necessitam tomar, haja vista os custos de algumas.

“Às vezes é porque quando a gente chega aqui não tem remédio, não é? Só é pior por isso, porque faltam remédios, aí eu tenho que ir buscar em outro canto. Às vezes tem, mas quando não tem eu vou pegar em outro canto". (14) 
"Tem remédio que não tem aqui não, às vezes falta e a gente precisa comprar. Aí às vezes é tão difícil não é? Porque tem remédio que é caro". (I8)

“[...] Pelo menos a medicação quando a gente vem pegar dá várias viagens toda semana e não tem os remédios para a gente. Porque nem todas as vezes que a gente precisa de uma medicação, a gente tem condições de ir a uma farmácia comprar toda a medicação que precisa. Porque lá em casa somos eu e meu esposo que precisa tomar medicação". (114)

O estatuto do idoso, em seu capítulo IV, do direito à saúde, artigo $15, \S 2^{\circ}$, diz que: "incumbe ao poder público fornecer aos idosos, gratuitamente, medicamentos, especialmente os de uso continuado, assim como próteses, órteses e outros recursos relativos ao tratamento, habilitação ou reabilitação"16 (p. 14). Logo, percebe-se que um direito assegurado por lei está sendo descumprido, prejudicando estas mulheres na garantia de sua saúde.

Outra pesquisa ${ }^{19}$ aponta que parte da renda dos idosos é utilizada para comprar medicamentos. Em virtude da falta de abastecimento constante nas farmácias das unidades, as pessoas que necessitam de medicações diárias precisam comprar ou interromper o consumo até que cheguem aos postos de saúde. Essa dimensão precisa ser refletida, já que a demanda por estes insumos tende a aumentar pela população que envelhece, especialmente a feminina.

Uma das diretrizes para o atendimento das necessidades do grupo em destaque está delineada no Pacto pela Saúde de 2006. Em uma de suas dimensões, o Pacto pela Vida, elege-se a saúde do idoso como uma das prioridades, elencando diretrizes para melhorar a atenção à saúde desse público por meio do provimento de recursos capazes de assegurar, entre outros aspectos, a qualidade da atenção 20 .

Esses direitos são desconsiderados quando há demora na marcação de consultas e exames, tornando a assistência prestada, a esta população, fragmentada. Algumas idosas precisam utilizar a pouca renda que recebem para providenciar procedimento particular. Quando há inviabilidade no pagamento desses exames, as mulheres acabam esperando longos períodos, ficando sujeitas a ter o seu problema de saúde agravado.

“[...] ela (fazendo referência à médica) me encaminhou para um reumatologista, [...] mas eu não consegui até hoje". (16)

“Eu acho mais ou menos, razoável. É por isso que às vezes quando eu preciso vou para uma consulta particular. Assim... Porque demora um exame, demora muito para marcar, aí eu vou e faço particular. A minha filha às vezes reclama porque eu não espero. Eu não espero porque eu estou precisando, então vou atrás. Sou aposentada então uso a aposentadoria para fazer meus exames particulares". (I36)

“[...] Só que hoje eu estou devido a essa questão da minha saúde ser muito pouca e eu não ter mais como esperar muito tempo, porque eu fico passando mal, eu procuro mais um médico particular. Estou sofrendo muito com esse problema porque a gente que é pobre vive de salário e não tem como pagar médico particular, mas aí eu não tenho mais paciência para vir para cá". (I20)

É notória a necessidade de rever a agilidade de determinadas condutas destinadas à população, especialmente a idosa. A utilização dos serviços de saúde apresenta um padrão diferenciado quanto ao uso do serviço público entre a população que envelhece, uma vez que as usuárias com renda familiar baixa e pouca escolaridade são as que mais procuram por este tipo de atendimento. Os planos privados de saúde, em geral, possuem uma clientela com melhores condições salariais ${ }^{17}$.

A necessidade de agendar e marcar consultas na unidade de saúde é entendida, por algumas mulheres, como um aspecto difícil de ser concretizado, uma vez que, para conseguirem ficha, precisam se deslocar em horários inapropriados, muitas vezes, se expondo a riscos. 
No presente estudo, muitas idosas abordam esta dimensão de forma negativa, pois gostariam que o horário fosse alterado, bem como aumentasse a quantidade de fichas para a marcação de procedimentos, melhorando, assim, o acesso aos serviços de saúde.

“[...] às vezes a gente tem dificuldade para marcar consulta, porque tem que vir de madrugada para pegar ficha, porque se não vier também não pega [...]. Às vezes eu tenho que sair de casa de 04h00min, 04h30min da manhã para vir para cá. E às vezes, muitas vezes, quando chega aqui não tem mais ficha, já tem muitas na frente também [...]". (I16)

“[...] Meu marido vem pegar a ficha de madrugada, de 04h00min da manhã ele está aqui para poder pegar uma ficha. Aí quando eu chego no outro dia, que é por ordem de chegada, também ele vem cedo para pegar a vez para eu poder vir [...]". (I24)

Alguns parâmetros - como a oferta de uma atenção de qualidade, incluindo a preferência no atendimento; a oferta de medicamentos, evitando descontinuidade no tratamento; mais eficiência na marcação de consultas e exames, de forma a contribuir definitivamente com a qualidade de vida e saúde destas pessoas - precisam ser revistos pelos serviços de atenção primária que atendem a população feminina que envelhece, pois as dificuldades estruturais, materiais e assistenciais têm limitado essa prática.

\section{Considerações finais}

A sociedade brasileira enfrenta um importante desafio nos próximos anos, pois a mudança no perfil populacional desvela a necessidade de se desenvolverem ações e práticas específicas, particularmente na atenção à saúde do idoso. Os serviços de saúde devem estar preparados para atender aos anseios da mulher que envelhece, pois a procura destes espaços tende a ser potencializada.

Apesar de existirem aspectos assistenciais que coadunam com as propostas e necessidades das mulheres idosas, como, por exemplo, a criação de grupos de idosos nos serviços de saúde e o desenvolvimento de práticas mais acolhedoras e de escuta, ainda há muito a ser feito. É preciso se pensar ações e estratégias que valorizem o contexto de vida da idosa e que contribuam para uma atenção eficaz.

Embora o estudo seja focal e procure desvelar um contexto específico, é possível inferir que, dentre os aspectos abordados, essa realidade não foge do contexto nacional. Mesmo respeitando as especificidades das localidades e do grupo no qual se atua, as necessidades acabam sendo similares nas raízes dos problemas de produção das políticas e práticas em saúde.

Assim, reforça-se a importância de refletir sobre o contexto institucional de produção dos saberes e práticas cotidianas. Aponta-se para questões estruturais e funcionais, desvelando aspectos micro e macro que se articulam na produção das ações. Em âmbito micro, surge a necessidade de uma melhor capacitação dos profissionais que atendem a mulher idosa, ampliando seus conhecimentos acerca de temáticas específicas para esta faixa etária. Essa dimensão tenderá a contribuir para um envelhecimento saudável, com manutenção da autonomia e qualidade de vida. Em âmbito macro, é preciso refletir que, para qualquer mudança, são imprescindíveis novas estruturas, materiais e equipamentos, apontando para a reorientação na destinação de verbas públicas, em particular, na saúde.

Embora essas dimensões, em alguma medida, extrapolem o limite do fazer individual, na sua aplicabilidade será possível resgatar a confiança nos serviços e nos trabalhadores de saúde por meio de condutas inovadoras, com reestruturação dos espaços, construção do vínculo e a adesão da idosa às práticas e procedimentos de rotina.

A carência real de adequações físicas e funcionais nos serviços, muitas vezes, tem dificultado uma atenção de qualidade para a idosa. Em face disto, a agilidade e disponibilidade viável de procedimentos diversos para essas usuárias deve ser priorizada na procura por melhorias no atendimento. É sabido 
que aspectos - como marcação de exames, prioridade no atendimento, falta de medicamentos, consultas rápidas e pouco resolutivas, estruturas físicas inadequadas, entre outros - necessitam ser melhorados.

Em primeira instância, é preciso reorganizar as práticas nos serviços, de forma a estabelecer dinâmicas assistenciais que abordem a mulher integralmente. Enfatizar a promoção da saúde, favorecendo o bem-estar desta população, com práticas mais articuladas e de corresponsabilização entre equipe multiprofissional e idosas, tenderá a proporcionar um atendimento mais efetivo e resolutivo. Tal aspecto necessita ser estimulado, uma vez que as práticas curativas em detrimento das preventivas ainda permanecem muito presentes na rotina dos espaços de saúde.

É fato que a temática não se esgota nessa dimensão. É preciso repensar, com propriedade, formas de reorientar o cotidiano dos saberes e das práticas na perspectiva de atender às necessidades sociais e de saúde do grupo de mulheres idosas no Brasil. Para tanto, faz-se necessário refletir acerca dos aspectos relacionados ao cotidiano do trabalho no serviço, desvelando as carências estruturais, econômicas e materiais para a efetivação da mudança. Apenas assim, será possível pensar em assistência de qualidade e que atenda ao grupo em destaque.

\section{Colaboradores}

Suzane Gomes de Medeiros foi responsável pela construção do artigo, elaboração do instrumento qualitativo, coleta, e análise dos dados. Fátima Raquel Rosado Morais orientou e contribuiu com a melhoria do artigo em todas as suas etapas de elaboração.

\section{Referências}

1. Ministério da Saúde. Atenção à saúde da pessoa idosa e envelhecimento. Brasília: MS; 2010. (Série Pactos pela Saúde 2006, v. 12).

2. Prado TMB. Proteção social à pessoa idosa no Brasil. In: Berzins MV, Borges $M C$, organizadores. Políticas Públicas para um país que envelhece. São Paulo: Martinari; 2012. p. 67-98.

3. Faleiros VP. A pessoa idosa e seus direitos: sociedade, política e constituição. In: Berzins MV, Borges MC, organizadores. Políticas Públicas para um país que envelhece. São Paulo: Martinari; 2012. p. 45-66.

4. Giacomin KC. Envelhecimento populacional e os desafios para as políticas públicas. In: Berzins MV, Borges MC, organizadores. Políticas Públicas para um país que envelhece. São Paulo: Martinari; 2012. p. 17-44.

5. Mafra SCT. A tarefa do cuidar e as expectativas sociais diante de um envelhecimento demográfico: a importância de ressignificar o papel da família. Rev Bras Geriatr Gerontol. 2011; 14(2):353-63.

6. Carreira L, Rodrigues RAP. Dificuldades dos familiares de idosos portadores de doenças crônicas no acesso à Unidade Básica de Saúde. Rev Bras Enferm. 2010; 63(6):939-9.

7. Moura MAV, Domingos AM, Rassy MEC. A qualidade na atenção à saúde da mulher idosa: um relato de experiência. Esc Anna Nery. 2010; 14(4):848-55.

8. Nunes DP, Nakatani AYK, Silveira EA, Bachion MM, Souza MR. Capacidade funcional, condições socioeconômicas e de saúde de idosos atendidos por equipes de Saúde da Família de Goiânia (GO, Brasil). Cienc Saude Colet. 2010; 15(6):2887-98.

9. Minayo MCS, organizador. Pesquisa social: teoria, método e criatividade. 30a ed. Petrópolis: Vozes; 2011. 
10. Farias RG, Santos SMA. Influência dos determinantes do envelhecimento ativo entre idosos mais idosos. Texto Contexto Enferm. 2012; 21(1):167-76.

11. Mourão PR. Tempo decorrido desde a última consulta: análise de um modelo estatístico aplicado ao caso das mulheres na Espanha. Rev Assoc Med Bras. 2011; 57(2):164-70.

12. Xavier AS, Koifman L. Educação superior no Brasil e a formação dos profissionais de saúde com ênfase no envelhecimento. Interface (Botucatu). 2011; 15(39):973-84.

13. Merighi MAB, Oliveira DM, Jesus MCP, Souto RQ, Thamada AA. Mulheres idosas: desvelando suas vivências e necessidades de cuidado. Rev Esc Enferm USP. 2013; 47(2):408-14.

14. Daher DV, Debona KV. Reelaborando o viver: o papel do grupo no cotidiano de mulheres idosas. Esc Anna Nery. 2010; 14(4):670-6.

15. Combinato DS, Dalla Vecchia M, Lopes EG, Manoel RA. "Grupos de conversa": saúde da pessoa idosa na estratégia saúde da família. Psicol Soc. 2010; 22(3):558-68.

16. Ministério da Saúde. Estatuto do idoso. 2a. ed. Brasília (DF): MS; 2007.

17. Pilger C, Menon UM, Mathias TAF. Utilização de serviços de saúde por idosos vivendo na comunidade. Rev Esc Enferm USP. 2013; 47(1):213-20.

18. Dallanezi G, Nahas EAP, Freire BF, Nahas-Neto J, Corrente JE, Mazeto GMFS. Qualidade de vida de mulheres com baixa massa óssea na pós-menopausa. Rev Bras Ginecol Obstet. 2011; 33(3):133-8.

19. Geib LTC. Determinantes sociais da saúde do idoso. Cienc Saude Colet. 2012; 17(1):123-33.

20. Conselho Nacional de Secretários de Saúde. Coleção para entender a gestão do SUS. Brasília (DF): CONASS; 2011. v. 1.

Medeiros SG, Morais FRR. Organización de los servicios en la atención de la salud de la mujer anciana: percepción de usuarias. Interface (Botucatu). 2015; 19(52):109-19.

Su objetivo es percibir los aspectos que interactúan en la asistencia a la mujer anciana en el municipio de Mossoró-Estado de Río Grande do Norte, Brasil, a partir de la perspectiva de las usuarias. Encuesta de naturaleza descriptiva y abordaje cualitativo, realizado con mujeres en el rango de edad de sesenta años o más que utilizan los servicios de atención básica seleccionados para el estudio. Después del análisis de las declaraciones, surgieron tres categorías: motivos que incentivan la búsqueda del servicio, orientaciones recibidas en los servicios de salud y problemáticas vividas cotidianamente en la búsqueda del servicio. La calidad de la atención a la mujer mayor requiere trabajadores capacitados; disminución de los obstáculos burocráticos, acciones y prácticas articuladas y continuas, incluyendo anhelos y expectativas de la mujer anciana.

Palabras-clave: Mujer anciana. Atención básica. Envejecimiento. 
